$\begin{array}{lll}\text { Journal of } & \text { Journal of Parathyroid Disease 2018,6(2),78-79 } & \text { Dol: } 10.15171 / \text { jpd.2018.25 } \\ \text { Parathyroid } & & \text { Commentary } \\ \text { Disease } & \end{array}$

\title{
The prevalence of vitamin $D$ deficiency is alarming high
}

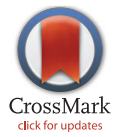

\author{
Seyed Majid Mousavi Movahhed ${ }^{1}$, Seyed Seifollah Beladi Mousavi ${ }^{*}$, Fatemeh Hayati ${ }^{2}$, Shokouh \\ Shayanpour ${ }^{2}$, Shahla Ahmadi Halili'², Leila Sabetnia ${ }^{2}$
}

\section{Dear Editor}

With great interest, we read the recently published article by Zaher Khazaei and colleagues entitled "Vitamin D deficiency in healthy people and its relationship with gender and age" in this journal (1). In this study, they measured serum vitamin D levels in a group of Iranian healthy individuals (102 participants) to evaluate the relationship between serum 25-hydroxy vitamin D with gender and age of participants (1).

The results of the study showed that vitamin $\mathrm{D}$ level is lower than $20 \mathrm{ng} / \mathrm{mL}$ in a significant percentage of healthy individuals $(73 \%)$ which was considered as vitamin D deficiency.

The levels of vitamin D in $18 \%$ of participants were between 20.1 to $29.9 \mathrm{ng} / \mathrm{mL}$ which were interpreted as a marginal deficiency. Therefore according to the results of this study, only $9 \%$ of the healthy individuals had normal vitamin D level and the prevalence of vitamin D deficiency among Iranian healthy individuals was alarming high (1). Similar to the results of Khazaei et al study, the results of other investigations which have performed in some other Asian countries like India and Pakistan showed that majority of people in these countries had severe vitamin D deficiency.

As an example, Rasul Khan and colleagues evaluated vitamin $\mathrm{D}$ status in patients presenting with a complaint of easy fatigability at a medical outpatient clinic. They showed that $92 \%$ of participants had low vitamin D levels. Vitamin D status was in the normal range in only $8 \%$ of the patients in the study by Rasul Khan et al (2). A similar percentage $(89.3 \%)$ of low vitamin D levels was also recorded from Northern Pakistan in the study by Mufti et al (3).

Although some data from Saudi Arabia showed that the Saudi population has better vitamin D status as compared to the above studies, however the other data from Saudi Arabia also revealed that majority of the patients had low vitamin D levels (4). As an example, Mirza et al evaluated vitamin D status in individuals with body aches at an outpatient department in Dammam, Saudi Arabia
Implication for health policy/practice/research/medical education

The prevalence of vitamin D deficiency is alarming high in the world and therefore specialists and general physicians have to be more educated about the causes of vitamin D deficiency.

Keywords: Vitamin D, 25-hydroxy vitamin D, Vitamin D deficiency

and showed that $98 \%$ of the patients had low vitamin D levels (4).

In contrast to the developing countries, it seems that the prevalence of vitamin D deficiency in developed countries like Germany and the United States is not as high as the results of the above studies and overt vitamin D deficiency, is uncommon in most of these countries $(5,6)$.

However, even in developed countries the prevalence of low vitamin D levels is increasing and is associated with osteoporosis, increased risk of falls, and possibly fractures (5).

In addition to healthy adults, vitamin $\mathrm{D}$ deficiency is also a prominent feature among patients with organ failure including chronic kidney disease and it may be associated with poor outcome of these patients (7-9).

In summary the prevalence of vitamin $\mathrm{D}$ deficiency is alarming high in the world and therefore specialists and general physicians have to be more educated about the causes of vitamin $\mathrm{D}$ deficiency.

There are several causes of symptomatic and or asymptomatic vitamin D deficiency in adults. Decreased dietary vitamin $\mathrm{D}$ intake is a common cause of vitamin $\mathrm{D}$ deficiency in developed and developing countries. According to the results of a study in France, more than one-third of postmenopausal women living in this country consumed less than 100 international units of vitamin D per day $(10,11)$.

Decreased absorption of vitamin D especially in patients with malabsorption disorders like inflammatory bowel disease and celiac disease, reduced sun exposure, lack of awareness regarding sun exposure, increased hepatic 
catabolism (for example taking medications that accelerate the metabolism of vitamin D such as phenytoin), decreased endogenous synthesis or end-organ resistance to vitamin $\mathrm{D}$ are other causes of vitamin D deficiency $(10,11)$.

\section{Authors' contribution}

All authors passed four criteria for authorship contribution based on recommendations of the International Committee of Medical Journal Editors. SSBM, FH, SS, LS, AAH and SMMM contributed equally to prepare of manuscript. All authors read and signed the edited manuscript.

\section{Conflicts of interest}

The authors declare that, they have no conflict of interests.

\section{Ethical considerations}

Ethical issues (including plagiarism, data fabrication, double publication) have been completely observed by the authors.

\section{Funding/Support}

None.

\section{References}

1. Khazaei Z, Khazaei S. Beigrezaei S, Nasri H. Vitamin D deficiency in healthy people and its relationship with gender and age. J Parathyr Dis. 2018; 6:16-18. doi: 10.15171/ jpd.2018.06.

2. Rasul Khan R, Mehmood Yahya K, Saqib A. Frequency of vitamin D deficiency in patients with fatigue. JUMDC.
2014;5:26-31.

3. Mufti MA, Malhi UR, Zubair A, Badar I, Mufti M. vitamin D level in adults in Northern Pakistan. Rawal Med J. 2012;37:2-5

4. Mirza J, Ali M. Vitamin D deficiency in outpatient department: Eastern province of KSA experience. Rawal Med J. 2010;35:221-3

5. Knutsen KV, Brekke M, Gjelstad S, Lagerlov P et al. Vitamin D status in patients with musculoskeletal pain, fatigue and headache: a cross sectional descriptive study in multi ethnic general practice in Norway. Scand J Prim Healthcare.2010; 28(3):166-71

6. Merlo C, Ross C, Trummler M, Zeller A. Prevalence and symptoms of vitamin D deficiency in general practice. Praxis (Bern 1994). 2012101:1417-22

7. Beladi Mousavi SS, Alemzadeh Ansari MJ, Cheraghian B. Outcome of Patients on hemodialysis in Khuzestan, Iran. NDT Plus. 2011; 4:143-144 .

8. Beladi Mousavi SS, Soleimani A, Beladi Mousavi M. Epidemiology of end-stage renal disease in iran: a review article. Saudi J Kidney Dis Transpl. 2014; 25:697-702.

9. Beladi Mousavi SS, Alemzadeh-Ansari MJ, AlemzadehAnsari MH. Long-term survival of patients with end-stage renal disease on maintenance hemodialysis: a multicenter study in Iran. Iran J Kidney Dis. 2012; 6:452-6.

10. Rawal G, Yadav S, Shokeen P. Health and the vitamin D. Int J Health Sci Res. 2015;5:416-23.

11. Kim SH, Oh MK, Namgung R, Park MJ. Prevalence of 25-hydroxyvitamin D deficiency in Korean adolescents: association with age, season and parental vitamin D status. Public Health Nutr. 2014;17:122-30. doi: 10.1017/ S1368980012004703.

Please cite this paper as: Mousavi Movahhed SM, Beladi Mousavi SS, Hayati F, Shayanpour S, Ahmadi Halili S, Leila Sabetnia L. The prevalence of vitamin D deficiency is alarming high. J Parathyr Dis. 2018;6(2):78-79. doi: 10.15171/jpd.2018.25.

Copyright (c) 2018 The Author(s); Published by Nickan Research Institute. This is an open-access article distributed under the terms of the Creative Commons Attribution License (http://creativecommons.org/licenses/by/4.0), which permits unrestricted use, distribution, and reproduction in any medium, provided the original work is properly cited. 